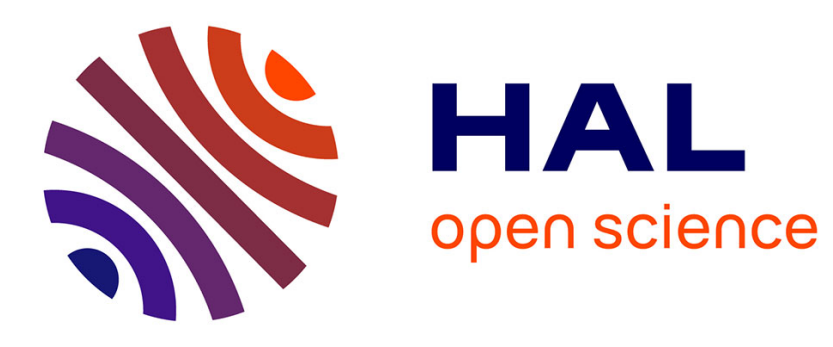

\title{
Role of graphics tools in the learning design process
}

Patrice Laisney, Pascale Brandt-Pomares

\section{To cite this version:}

Patrice Laisney, Pascale Brandt-Pomares. Role of graphics tools in the learning design process. International Journal of Technology and Design Education, 2014, 10.1007/s10798-014-9267-y . hal01437454

\section{HAL Id: hal-01437454 \\ https://hal.science/hal-01437454}

Submitted on 20 Jan 2017

HAL is a multi-disciplinary open access archive for the deposit and dissemination of scientific research documents, whether they are published or not. The documents may come from teaching and research institutions in France or abroad, or from public or private research centers.
L'archive ouverte pluridisciplinaire HAL, est destinée au dépôt et à la diffusion de documents scientifiques de niveau recherche, publiés ou non, émanant des établissements d'enseignement et de recherche français ou étrangers, des laboratoires publics ou privés. 


\title{
Role of graphics tools in the learning design process
}

\author{
Laisney Patrice Ï Brandt-Pomares Pascale \\ patrice.laisney@univ-amu.fr \\ pascale.brandt-pomares@univ-amu.fr
}

Abstract: This paper discusses the design activities of students in secondary school in France. Graphics tools are now part of the capacity of design professionals. It is therefore apt to reflect on their integration into the technological education. Has the use of intermediate graphical tools changed studentsôperformance, and if so in what direction, in phase of seeking solutions through a design activity in a situation of teaching and learning?

The influence of Computer Aided Design (CAD) tools on design professional activities has been the subject of much research, but little has focused on student activity. Thus, analysing student work through an experimental device, we ask that students produce more solutions without using CAD tools. Do CAD activities encourage the modelling of a particular solution? Does drawing by hand before $\mathrm{CAD}$ activities support the production of various solutions and define them more precisely? Through the analysis of solutions developed by students, including traces of their activity (sketches, digital files), we test our hypotheses.

Keywords: Technological education ï Problem-solving ï Computer Aided Design ï graphical tools

\section{Introduction}

This paper presents a study of the activity of students when faced with situations which require solving design problems. We focused on the role of graphical tools. More specifically, the paper considers the relationship between sketch realization (hand-drawing) and the use of CAD tools in the activity of students, especially in the early stages of research. Through analysis of drawings made by students as they use or do not use CAD tools, we try to understand the creative process they employ.

The findings of this study relate to the fact that it is important to consider the introduction of these tools in promoting and facilitating the process of finding solutions. Our results confirm our hypothesis that hand-drawing $\ddot{i}$ as is the case for architects and designers $\ddot{i}$ favours a broader search for solutions. The introduction of a second phase, CAD tools, provides a model of the object that is 
enriched due to the assistance the tools provide to students. As such, CAD is required in the process of object design.

The scope of this research and its findings is contingent to situations, problems and specific tools. But we consider that it is possible to consider a few factors that contribute to the understanding the teaching-learning of design process.

\section{Design learning in technology education in France}

In the French education system, technology teaching curriculums in secondary school for pupils of about 12 years old rely on exploring a context called r̃ousing and structureò, so that pupils can analyse and create their own technical items. They are supposed to represent the technical solutions they have come up with, either through handmade sketches or by using Computer Aided Design (CAD) tools. Information Technology (IT) tools seem all the more appropriate as they are widely used both in the teaching of technology and by design professionals. Therefore our aim is mainly to assess the input of IT techniques in 12-year-oldsô skill-building process. Observation shows how design teaching in secondary schools usually takes place in France. Pupils usually learn through extremely specifically directed situations by the teacher. Most of the time, they are asked to follow certain predefined steps without really having to resort to the use of any problem-solving techniques. The span of creativity they might have is consequently limited, especially with regard to designing and producing varied solutions to the problem.

Most of the time, the role of graphical tools is not questioned by the teachers. If the CAD tools are supposed to serve the activity designer, teachers do not always question their interest in learning. Is that CAD tools are adapted to pupils? Do they facilitate finding solutions by pupils? CAD tools are essential today for the designer, but they should be analysed in terms of their impact on studentsô learning process. Their introduction into situations is systematic and their articulation with other tools, such as drawing sketches by hand or making mock principle is only slightly observed and analysed. 


\section{Model for analysing teaching of design activity}

\section{Problem-solving and design}

According to the model proposed by De Vries (2005), the design approach focuses on the technological process in which students solve undetermined problems. For all that the situations which it is advisable to propose again are to be defined, because the resolution of problems does not decree (Ginestié, 2005, 2010). In particular, offered to students in technology education situations should be designed to provide a variety of possible solutions. Envisaged in the reality of the functioning of the class, the professor acts as a strong guide of the action, indicating to the pupils what they have to do to arrive at the required result, going as far as indicating to them ways of arriving at a solution (Hérold \& Ginestié, 2009).

The work driven by Arsac, Germain and Mante (1991) in didactics of mathematics proposes a distinction between open problems and closed problems. While closed problems tend to imply only a single possible solution, open problems admit several hypotheses for resolution. For our study, we shall retain this distinction for teaching related to the resolution of problems. Design is a matter of resolving rather ñopenò problems; that is, it is about a problem to which the solutions are infinite. In this case the pupil is confronted with the choices of the shape, these sizes, the structure of the object, as well as used materials. To study the variety in pupilsôwork particularly when they are confronted with an open problem, we shall distinguish three notional fields which make by Rabardel and Vérillon (Rabardel \& Vérillon, 1987; Rabardel, 1989) in the technical drawing: geometry, technology and code. Geometry suggests the forms of the objects represented; morphology and dimensions. Technology suggests the characteristics of the subject; the relative movements of the constituent parts, their structure and the functions of the forms. Code, which articulates with the previous two notional fields, is not the object of our study, which concerns traditional drawing and CAD. As it does not involve the same tools of representation, it does not allow comparison. 


\section{Creative design, a model for design activity}

The general model of the design activity borrowed from Lebahar (1983) identifies three main stages to describe the process of architectural design. This general model of the cognitive aspects of design assimilates this activity in ñresolution of badly defined problemsò (Simon, 1991) and is characterized by ñcreative designò. This notion of creativity develops through the mechanisms which it involves: exploration, generation of solutions and evaluation. But especially, this model takes into account an essential aspect of design activity, which concerns drawing under all its forms, including with the use of computing tools. The drawing is at the same time a representational medium and a tool of thought. More precisely, the sketch is considered as an integral part of the creative design activities. It is defined as the dominating tool of thought. Drawing is indeed seen by specialists in cognitive psychology (Goël, 1995; Schon, 1983) as a representation of mental activity, fixing the ideas in the first phases of design. But more than that, these drawn visual representations, which take several forms following the design phases, are recombined, modified and adapted. In Lebaharôs model, graphic intermediaries appear in each of the stages:

i) The architectural diagnosis. In this first phase the architect seeks to identify and define the problem to be solved with regard to the constraints. He is then in the phase of exploration and the result will be a first graphic ñbase of simulationò, a mix of notes and first drawings.

ii) Research for the object through graphic simulation. From then on, the designer is going to work on generation of the solutions and their evaluation, in an incremental and iterative process. It is the drawing which is going to be the privileged vector of this approach. It represents, as underlined by Lebahar, ñthe object in creation and the thought which creates itò.

iii) The establishment of the model of construction. In this phase the designer defines precise graphic representations, intended to make clear the solution for the builders. It is the ñdefinitive decisionò concerning the whole project (plans, precise drawings with a specified scale, etc.).

Rabardel and Weill-Fassinâ̂ (1992) work on the implementation of graphics systems allows us to consider the analysis of graphics intermediaries involved in all three stages of Lebaharôs model in a triple point functionally, semiotic and cognitive. The graphics are intermediate semiotic objects embedded in complex 
tasks that are functional to the task at hand. For example the shapes, the size, the subject, the structure or the function are among the aspects of the object useful for the designer action. This action raises various transformations operated on the subject (manufacturing, assembly) as well as mental operations of treatment of the information inherent to the resolution process of design problems. So, the drawing is a tool, an instrument which the subject uses to solve design problems. Design is so considered as a creative process of an object by progressive elaboration of a mental representation and a representation of this object by the subject.

\section{The role of the graphic tools}

Lebahar $(1996,2007)$ studied the place of the tools of CAD $i ̈$ in particular where articulation enters traditional drawing ñby handò and modelling by means of CAD software. ñWhitefield showed, by comparing the works of industrial designers drawing by hand, in those produced by designers using a CAD system, that the first ones tended to investigate several possibilities of alternative solutions (strategy in width), while the second, more concentrated on their operations of modeling on computer, more got into detail and developed only a unique solution, during all the process (in-depth strategy)ò (Lebahar, 2007, free translation, p. 146). According to Lebahar, ñstrategy in widthò is rather connected to drawing by hand, while the in-depth strategy depends on the implementation of a CAD system.

Other research on the use of CAD software by industrial designers (Bonnardel \& Zenasni, 2010; Bonnardel, 2009; Chester, 2007; Asperl, 2005) shows that current CAD software does not support creativity and is after all only a range of ñcomputing techniquesò. First of all at the cognitive level, their methods of construction of a digital model tend to impose choices on the user and do not base themselves on the indistinct data of the design initial phases; this is reflected by the fact that the designer is forced at an early stage to handle specific geometric entities. The systems do not know how to manipulate vague, indistinct data characteristic of the problem-solving stage. At the contextual level, meanwhile, the modes of representation and interaction paradigms they offer do not place the user in an optimal context for creation.

We underlined the importance which holds the drawing in the design first phases as the "freedom" which it infers in the generation of the solutions to a problem, 
essentially thanks to an intuitive relationship with the designer. He goes away nevertheless in quite a different direction for the CAD software.

At this stage, these studies show that while CAD tools are sophisticated, it is still beneficial to incorporate hand-drawings in the design activity, and especially in the teaching of technology.

From the point of view of the teaching-learning processes, Martin (2007) shows the contribution that can be made to schools by computing tools which aid the learning of drawing. The use of a digital tool can help the children while they copy a model, but does not improve their capacity to use their own internal model. At middle school level, Pektas and Erkip (2006) show the necessary level of ñfamiliarizationò with $\mathrm{CAD}$ tools to favour pupilsôcommitment in the design task, as well as the role of the representations. All these works agree on the fact that on one hand, the computing tools must be adapted to the teaching-learning process, and on the other, it is important to take into account the representations in every stage of the process.

To conclude, this study is interested in the development of design activities by pupils within the framework of technology education, which traditionally centers on the use of tools (Brandt-Pomares, 2011). We propose to use a model built by considering a ñgrey areaò in which the use of traditional design or CAD tools will help the process of finding solutions for pupils of middle school. This ñgrey areaò corresponds to this particular time students spend a drawing tool to another and we intend to understand. We think that creativity could be expressed through the variety of solutions developed by pupils.

At the methodological level, we propose to analyze the student activity. The analysis of the activity has been described in many studies (Vygotsky, 1962; Leontiev, 1972; Engeström, 2005). Itố a way to look at what the teacher asks to work through it offers to students and what pupils actually do.

\section{Method}

Assuming that the recourse to CAD tools or to the drawing "by hand" influence looks for the solutions, we make the hypothesis that recourse to drawing ñby handò favours the shaping of a bigger variety of solutions, while the use of the CAD tool particularly favours the deepening of a solution. As a result, the order in which the pupils would be advised to use these tools would also have an 
influence. Preceding CAD activity with an activity without recourse to computing tools should end in the production of valid solutions with regard to the constraints i more numerous, more varied and defined, with more precision at the end of the process. We therefore formalize the following three operational hypotheses:

- H1: the pupils produce more solutions when not using the CAD tools.

- $\mathrm{H} 2$ : the CAD favours the modelling of one solution in particular.

- H3: drawing by hand prior to the CAD activity favours the production process of solutions (several possibilities and more detail).

\section{Research plan}

The observation device object has been designed in collaboration with four technology teachers who agreed to participate in the experiment.

To test our hypotheses, we proposed a plan in which the pupils are requested to solve an open problem. The teachers ask their pupils to design a coffee table. The following instruction was given to the pupils: ñYour work consists of proposing solutions to create the table by respecting the constraints of the specificationsò. It should be noted that teachers were asked to intervene as little as possible and avoid guiding the actions of pupils. The specifications given to students are as follows in table 1:

\begin{tabular}{|c|l|}
\hline \multicolumn{2}{|l|}{ Indoor use (coffee table for living room) } \\
\hline Using innovative materials, preferably translucent (glass, translucent resins) \\
\hline \multicolumn{2}{|l|}{ The cost price is not considered } \\
\hline Forms & $\begin{array}{l}\text { Contemporary design } \\
\text { The top plate of the coffee table should be flat } \\
\text { The table must be stable (does not tip easily) }\end{array}$ \\
\hline Dimensions & $\begin{array}{l}\text { Overall dimensions: } 1000 \times 500 \times 500 \\
\text { Minimum size tray: } 950 \times 450 \\
\text { Position the plate: } 400<\mathrm{Pp}<500\end{array}$ \\
\hline
\end{tabular}

Table 1: Specifications

We analysed the productions realized by more than 200 pupils of 5 th (pupils aged 12) distributed on 4 middle schools (10 divisions) in France confronted with a design task. Table 2 presents the distribution of the tested population. 


\begin{tabular}{|c|c|c|c|c|}
\hline Middle school & 1 & 2 & 3 & 4 \\
\hline $\begin{array}{c}\text { Nb of divisions } \\
\text { Nb of pupils }\end{array}$ & 2 & 3 & 2 & 3 \\
\hline $\begin{array}{c}\text { Google } \\
\text { SketchUp }\end{array}$ & \multicolumn{2}{|c|}{ Prior experience } & No prior experience \\
\hline
\end{tabular}

Table 2: Tested pupil population

The entire test population consists of pupils from these 10 divisions. Similarly, classes are divided into two groups, A and B, which are balanced (no group level) and correspond to those established by the teacher who has responsibility within the institution.

Table 3 presents the three working modalities corresponding to what the pupils had to make during two 50-minute sessions.

\begin{tabular}{|c|c|c|}
\hline Sessions & Group A & Group B \\
\hline \multirow{2}{*}{1} & Modality 1 & Modality 2 \\
& ñby handò & ñSketchUpò \\
\hline 2 & \multicolumn{2}{|c|}{ Modality 3 } \\
& \multicolumn{2}{|c|}{ ñfreedom of choiceò } \\
\hline
\end{tabular}

Table 3: Plan of the experimental device

We want to implement tools already used by teachers, which are recommended on the various sites of academic resources for technological education in France. Google SketchUp software, based on features inspired by traditional ñintuitiveò design, seems to offer a quick route to learning.

During the first session (modality 1), group A has to realize the design task by exclusively using the traditional method of drawing ñby handò. Meanwhile, group B (modality 2) has to realize the same task by exclusively using the SketchUp Google software. During the second session (modality 3) both groups (A and B) are again confronted with the same task; that is, they have to pursue their research to find solutions, but this time they have the freedom to choose the graphic representation tools. To verify the impact that the pupilsôfamiliarization with the software could have, we shall test two populations of pupils: those who ñknow itò, because they have already used it within the framework of teaching realized by the teacher during the previous sessions, and those who ñdiscover itò. 


\section{Data and analysis indicators}

The pupils made their graphic productions in the conditions of an ordinarily functioning middle school technology course of technology in the middle school, in class and with their usual teacher. At the end of sessions 1 and 2 and for each of modalities 1, 2 and 3, all the written and digital files produced by the pupils were collected.

We coded the various solutions according to their geometry (forms), technology (structures), assembly (mobility) and materials used. From the choices made and their combination, we can determine all the solutions to this problem. Indeed, there are three solutions at least for the choice of shape, four solutions for structures with fixed or mobile parts, with a number of feet which can vary (1ï 4 or more), and finally an open choice of materials (metal, wood, plastic, glass). Altogether, there are more than three hundred solutions. Illustration 1 proposes an example of a solution corresponding to the following coding: F3 (egg-shaped), S2 (tubular structure), 1 center foot, fixed assembly and M2 (several used but unspecified materials).

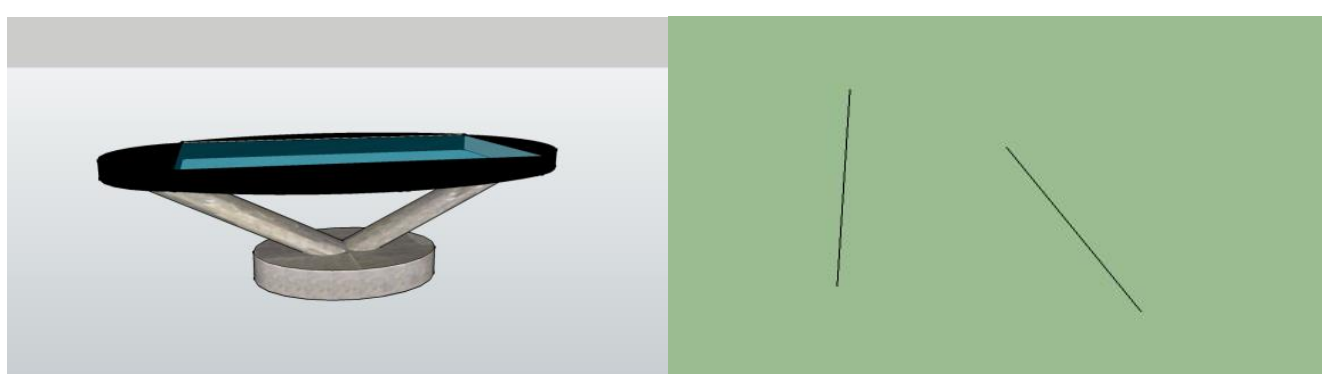

Illustration 1: Example of solution (to the left) and production (to the right)

Concerning the first hypothesis, the indicators are the numbers of productions and solutions represented by the pupils according to the tool used. Every paper or computer file developed by the pupils will be called a production, whatever its state of elaboration; that is, for example, even if it is a simple sketch or an incomplete digital model. Any production will be considered as an eligible solution; that is, a possible solution to the problem posed. An eligible solution is not necessarily at this stage a finalized solution to the problem. The numbers of productions and solutions so found during the three modalities of the experimental plan will allow the comparison between both groups $\mathrm{A}$ and $\mathrm{B}$.

Concerning the second hypothesis, the indicator is the state of elaboration of the models represented by the pupils of both groups A and B, in three modalities. It 
will take into account the dimensional respect through manipulation of the scale of representation, the presence of decoration elements and material texture and the deepening of a unique solution deducted from the number of solutions developed by pupil.

Finally, concerning the third hypothesis, the indicators are of three kinds: the variety of the solutions developed in three modalities, graphic tools chosen and used in the third (free) modality and the evolution of the solutions between the sessions 1 and 2 for groups A and B. The variety of solutions will be measured with regard to the diversity of the proposals. The evolution of the solutions will be considered according to three categories: ñidenticalò if we notice no change in the choices, ñevolutionò if we notice only minor changes and finally ñnewsò if choices are different.

\section{Results and data analysis}

\section{Number of productions and solutions}

Each production by a pupil is identified as the result of a work which ends in the realization of graphic. The productions retained as solutions include only the graphic tracks which represent a structural organization of forms admitting a plane surface (Illustration 2).
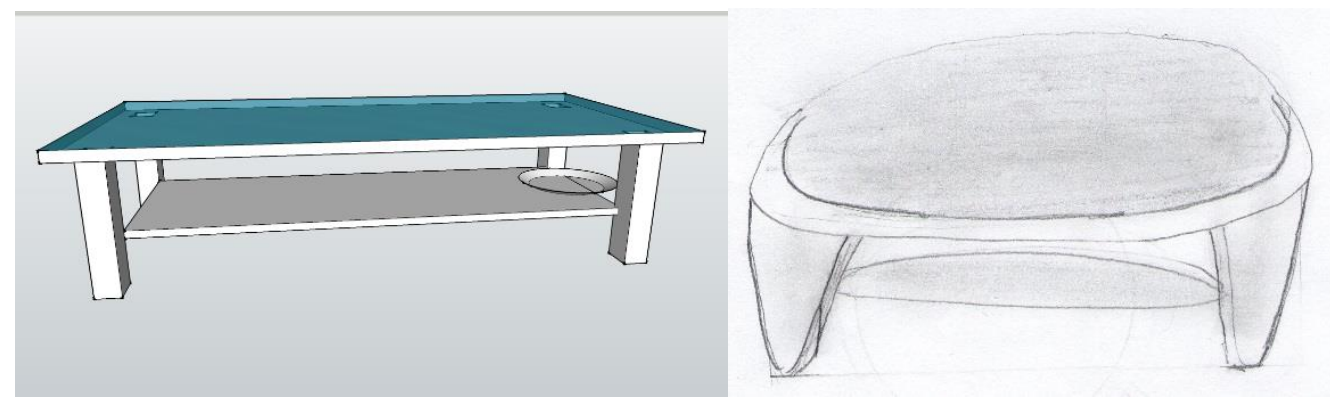

Illustration 2: Example of solution with SketchUp (to the left) and by hand (to the right)

We counted the number of ñsolutionsò produced by the pupils. The number of productions and solutions developed by all the pupils at the end of the first session appear in tables 4 ï 6 .

\begin{tabular}{|c|c|c|c|}
\hline Session 1 & Nb of pupils & Productions & Solutions \\
\hline Group A & 105 & 243 & 222 \\
\hline Group B & 98 & 112 & 81 \\
\hline
\end{tabular}

Table 4: Number of productions and solutions elaborated 
The analysis of the number of productions and solutions confirms our first hypothesis, according to which the pupils produce more solutions without using the CAD tools. Indeed, on one hand table 4 shows that the pupils in group A realize more productions and solutions than the pupils in group B, while on the other, tables 5 and 6 show that this difference is not due to any pupils in particular but to a general tendency which concerns the majority of the pupils. The pupils in group A are capable of developing mainly more than a production (or solution) while the pupils of the group B do not rarely propose it any more of one.

\begin{tabular}{|c|c|c|c|}
\hline Session 1 & 1 production & 2 productions & +2 productions \\
\hline Group A & 16 & 64 & 25 \\
\hline Group B & 89 & 6 & 3 \\
\hline Total & 105 & 70 & 28 \\
\hline
\end{tabular}

Table 5: Number of productions developed by pupil

\begin{tabular}{|c|c|c|c|}
\hline Session 1 & 1 solution & 2 solutions & +2 solutions \\
\hline Group A & 26 & 57 & 22 \\
\hline Group B & 68 & 3 & 2 \\
\hline Total & 94 & 60 & 24 \\
\hline
\end{tabular}

Table 6: Number of solutions developed by pupil

Our methodological precaution, with no level group, is confirmed by statistical test. Confirmatory tests show, as seen in table 4, that both groups are equivalent in terms of constitution $(\mathrm{Khi} 2=0.059 ; \mathrm{Ddl}=1 ; \mathrm{p}<0.05)$. More than that, we think it is not the composition of the group that influences the number of productions and solutions, but well the roles which play the graphic intermediaries in the tasks made. Nevertheless, we observe in tables 5 and 6 significant differences (Khi2 $=$ 115,992 and $\mathrm{Khi} 2=76,786$; Ddl $=2 ; \mathrm{p}<0.05$ ) which we attribute to the task and the fact that in one case the pupils use the traditional method of drawing ñby handò, while in the other they use CAD tools.

\section{Difference between knowledge and discovery of the software}

In order to look to the effects of pupilsôlevel of familiarization with the software, we differentiated the population into two groups: those who knew it (Prior experience) and those who discovered it (No prior experience). Table 7 gives the 
number of productions and solutions developed by the pupils in group B at the end of the first session.

\begin{tabular}{|c|c|c|c|c|}
\hline \multicolumn{2}{|c|}{ Session 1 } & Nb of pupils & Productions & Solutions \\
\hline \multirow{2}{*}{ Group B } & $\begin{array}{c}\text { (No prior } \\
\text { experience) }\end{array}$ & 46 & 58 & $\mathbf{3 5}$ \\
\cline { 2 - 5 } & $\begin{array}{c}\text { (Prior } \\
\text { experience) }\end{array}$ & 52 & 54 & $\mathbf{4 6}$ \\
\hline \multicolumn{2}{|c|}{ Total } & 98 & 112 & 81 \\
\hline
\end{tabular}

Table 7: Number of productions and solutions developed by group B

The number of productions and solutions realized by pupils in group B who discovered the software and those who know it is of the same order. If the number of elaborate solutions (46) by the pupils who know the software is upper among elaborate solutions (35) by the pupils who discover the software, however, the test of Khi2 shows that this difference is not statistically significant between both groups $(\mathrm{Khi} 2=1.385 ; \mathrm{Ddl}=1 ; \mathrm{p}<0.05)$, what allows us to retain the hypothesis of homogeneity of both groups. We conclude that both groups are similar in composition and that the differences found at the level of number of productions and solutions are due to the conditions of task realization.

\section{Evolution of solutions developed}

Finally we look at the process of developing solutions for pupils. Table 8 presents the evolution of solutions between the two sessions, according to groups A and B, by differentiating the levels of familiarity with Google SketchUp.

The analysis of the evolution of solutions between session 1 and session 2 shows that pupils in group B did not explore new solutions to a greater degree than those in group A. Especially pupils who knew the software with $52 \%$ identical solutions and only $18 \%$ for the group A. This allows us to say that hand-drawing before CAD use seems to favour the extension of research into solutions for pupils familiar with the software. In contrast, for pupils who discover the CAD tool, despite the additional burden for them in using Google SketchUp, the order in which the tools are introduced does not seem to affect their performance in the process of searching for a solution. 


\begin{tabular}{|c|c|c|c|c|}
\hline Solutions & \multicolumn{4}{|c|}{ Session 2 (Group A) } \\
\hline Identical & 10 & $18 \%$ & 6 & $7 \%$ \\
\hline Evolution & 18 & $32 \%$ & 18 & $22 \%$ \\
\hline News & 29 & $51 \%$ & 59 & $71 \%$ \\
\hline Solutions & \multicolumn{4}{|c|}{ Session 2 (Group B) } \\
\hline Identical & 34 & $52 \%$ & 7 & $8 \%$ \\
\hline Evolution & 9 & $14 \%$ & 17 & $20 \%$ \\
\hline News & 23 & $35 \%$ & 60 & $71 \%$ \\
\hline Google SketchUp & \multicolumn{2}{|c|}{ Prior experience } & \multicolumn{2}{|c|}{ No prior experience } \\
\hline
\end{tabular}

Table 8: Evolution of solutions of the session 1 to session 2 (modality 3 )

\section{Conclusions}

For an ñopenò design problem, in this particular case designing a coffee table, the exploration phase of the search for a solution grows rich by using drawing ñby handò. Indeed, the use of traditional drawing in the early stages of finding solutions allows pupils to shape blanks solutions to design problem. The pupils are all capable of producing drawings which allow the expression of their ideas. The results of the experiment tend to show that the use of traditional drawing before $\mathrm{CAD}$ tools are used allows the pupils to develop quantitatively more solutions. The Google SketchUp software seems to be considered early in the process of finding solutions. We note nevertheless that in this case, the exploration of the field of the possible is reduced and the pupils aim at a unique solution.

From indicators to analyze the variety of solutions developed by the two groups, we did not note any difference in the diversity of their proposed solutions. According to the pupilsôlevel of familiarization with the CAD tool, the passage from one medium to another is not made in the same way. It was found that pupils who discover the software will combine the manual while others abandon completely resulting in a lower volume of responses drawing. In addition, pupils who do not have a sufficient level of familiarity are not able to solve such a problem and design a large part of their cognitive resources is then used to take control of the software. To conclude, this work shows that when the graphical tools afford more than they constrain, they widen the field of the possible. 


\section{References}

Arsac, G., Germain, G., \& Mante, M. (1991). Probleme ouvert et situation-probleme. Villeurbanne: Institut de recherche pour l'enseignement des mathexatiques.

Asperl, A. (2005). How to teach CAD. Computer-Aided Design and Applications, 2(1), 459-468.

Bonnardel, N., \& Zenasni, F. (2010). The impact of technology on creativity in design: an enhancement? Creativity and Innovation Management, 19(2), 180-191.

Bonnardel, N. (2009). Design activities and creativity: from the analysis of cognitive factors to creative design support. Travail Humain, 72(1), 5-22.

Brandt-Pomares, P. (2011). Technological education: the issue of information retrieval via the internet. In C. Benson \& J. Lunt (Eds.), International Handbook of Primary Technology Education; Rewiewing the Past twenty years (pp. 151-166). Birmingham: Sense Publishers.

Chester, I. (2007). Teaching for CAD expertise. International Journal of Technology and Design Education, 17(1), 23-35.

De Vries, M. (2005). Teaching about technology. an introduction to the philosophy of technology for non-philosophers. Dordrecht: Springer.

Engeström, Y. (2005). Developmental work research: Expanding activity theory in practice. Berlin: Lehmanns Media.

Ginestié, J. (2005). Résolutions de problèmes en éducation technologique. Éducation technologique, 28, 23-34.

Ginestié, J. (2010). How pupils solve problems in technology education and what they learn. In M. Barak \& M. Hacker (Eds.), Fostering human development through engineering and technology education (pp. sous presse). Rotterdam: Sense Publisher.

Goël, V. (1995). Sketches of thought. Cambridge, MA, USA.

Hérold, J.-F., \& Ginestié, J. (2009). Help with solving technological problems in project activities. International Journal of Technology and Design Education, On line first (12/12/09), 1-16. doi: $10.1007 /$ s10798-009-9106-8

Lebahar, J.-C. (1996). Simulation activity of CAD draftsman during a design task. Travail Humain, 59(3), 253-275.

Lebahar, J.-C. (2007). La conception en design industriel et en architecture. Désir, pertinence, coopération et cognition. Paris: Hermès-Lavoisier.

Leontiev, A. N. (1972). Activité, conscience, personnalité (2eme ed.). Moscou: Editions du Progrès.

Martin, P. (2007). Instrumentation, créativité en éducation artistique: Le cas de l'utilisation des outils de création numérique à l'école. Doctorat, Université de Provence, Aix-en-Provence. Available from Atelier National de Reproduction des Thèses, Lille.

Pektas, S. T., \& Erkip, F. (2006). Attitudes of design students toward computer usage in design. International Journal of Technology and Design Education, 16(1), 79-95.

Rabardel, P. (1989). Recherche en psychologie et en didactique: un exemple d'interaction dans l'enseignement du dessin technique. Revue française de pédagogie, 89, 55-62. 
Rabardel, P., \& Vérillon, P. (1987). Approches fonctionnelles du dessin technique: réflexions pour un cadre d'analyse. In P. Rabardel \& A. Weill-Fasina (Eds.), Le dessin technique (pp. 209-217). Paris: Hermès.

Rabardel, P., \& Weill-Fassina, A. (1992). Fonctionnalités et compétences dans la mise en î uvre de systèmes graphiques techniques. intellectica, 15 .

Schon, D. A. (1983). The reflexive practitioner: How profesionals think in action. New York: Basic Books.

Simon, H. A. (1991). Sciences des systèmes Sciences de lârtificiel (Réédition de 1969 ed.). Paris: Dunod.

Vygotski, L. S. (1962). Thought and language. New York: Wiley. 